\title{
Managing patients taking edoxaban in dentistry
}

\author{
Adrian Curto ${ }^{1}$, Daniel Curto ${ }^{2}$, Jorge Sanchez ${ }^{3}$ \\ ${ }^{1}$ Proffesor in Pediatric Dentistry. Faculty of Medicine, University of Salamanca, Salamanca, Spain \\ ${ }^{2}$ Student in Medicine. University of Salamanca, Salamanca, Spain \\ ${ }^{3}$ Master in Oral Surgery. Alfonso X El Sabio University, Madrid, Spain
}

Correspondence:

Faculty of Medicine - University of Salamanca

Alfonso X El Sabio, s/n

37007 - Salamanca, Spain

adrian_odonto@usal.es

Curto A, Curto D, Sanchez J. Managing patients taking edoxaban in dentistry. Systematic review. J Clin Exp Dent. 2017;9(2):e308-11. http://www.medicinaoral.com/odo/volumenes/v9i2/jcedv9i2p308.pdf

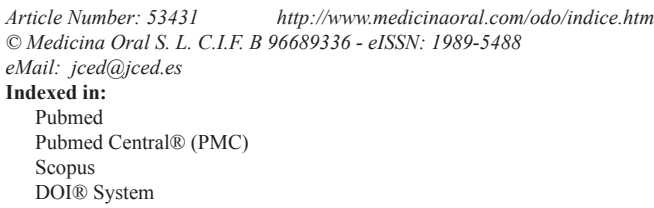

\begin{abstract}
Background: Anticoagulation therapy is used in several conditions to prevent or treat thromboembolism. A new group of oral anticoagulants with clear advantages over classic dicoumarin oral anticoagulants (warfarin and acenocoumarol) has been developed in recent years. The Food and Drug Administration has approved edoxaban, dabigatran, rivaroxaban and apixaban. Their advantages include: predictable pharmacokinetics, drug interactions and limited food, rapid onset of action and short half-life. However, they lack a specific reversal agent.

Material and Methods: This paper examines the available evidence regarding rivaroxaban and sets out proposals for clinical guidance of dental practitioners treating these patients in primary dental care. A literature search was conducted through July 2016 for publications in PubMed and Cochrane Library using the keywords "edoxaban", "dabigatran", "rivaroxaban", "apixaban", "new oral anticoagulants", "novel oral anticoagulants", "bleeding" and "dental treatment" with the "and" boolean operator in the last 10 years.

Results: The number of patients taking edoxaban is increasing. There is no need for regular coagulation monitoring of patients on edoxaban therapy. For patients requiring minor oral surgery procedures, interruption of edoxaban is not generally necessary. Management of patients on anticoagulation therapy requires that dentists can accurately assess the patient prior to dental treatments.

Conclusions: Their increased use means that oral care clinicians should have a sound understanding of the mechanism of action, pharmacology, reversal strategies and management of bleeding in patients taking edoxaban. There is a need for further clinical studies in order to establish more evidence-based guidelines for dental patients requiring edoxaban.
\end{abstract}

Key words: Edoxaban, dabigatran, rivaroxaban, apixaban, novel oral anticoagulants, bleeding. 


\section{Introduction}

There are a large number of patients being treated with oral anticoagulants and antiplatelet drugs. Oral anticoagulation and prevention of venous thromboembolism has been possible for decades thanks to the use of vitamin $\mathrm{K}$ antagonists, mainly warfarin and acenocoumarol (1). Vitamin K antagonist oral anticoagulants have a narrow therapeutic window, requiring regular International Normalized Ratio (INR) monitoring, and they also have several drug-drug and drug-food interactions. These disadvantages compromise patients' quality of life (2).

A great number of medical emergencies as a result of bleeding complications, especially in elderly individuals, are related to the administration of anticoagulant drugs that are vitamin $\mathrm{K}$ inhibitors. In the USA, these drugs are the most frequently involved in such emergency hospitalizations (3).

Research to find an alternative to classic oral anticoagulants has been focused on the development of an oral anticoagulant with a wide therapeutic window and little inter- and intra-individual variability that may be administered as a fixed-dose with no need for regular coagulation monitoring and few drug-drug and drug-food interactions. There are currently three direct factor Xa inhibitors (rivaroxaban, apixaban and edoxaban) and one direct thrombin inhibitor (dabigatran) with approved indications for antithrombotic prophylaxis and therapy in different conditions. Among these, the most recently developed and marketed oral anticoagulant is edoxaban.

The ENGAGE AF-TIMI 48 (effective anticoagulation with factor Xa next generation in atrial fibrillation) study is a randomized double-blind clinical trial that assessed the administration of edoxaban vs warfarin on a daily basis in a total of 21,105 patients with nonvalvular atrial fibrillation. The results proved that the efficacy of warfarin for the prevention of stroke and systemic embolism was noninferior to warfarin, and that the administration of edoxaban is associated with less morbidity (lower incidence of bleeding) (4). With regard to the ages of the patients taking part in the study, both for the risk of stroke or systemic embolism, and for major bleeding, the results for both doses of edoxaban were consistent, regardless of this factor ( $<75 \mathrm{vs} \geq 75$ years of age). In terms of International Normalized Ratio (INR) control, both for the risk of stroke and systemic embolism, and for that of major bleeding, the results were consistent for both doses of edoxaban, regardless of time in the therapeutic range ( $>66.4 \% \mathrm{o} \leq 66.4 \%$ ), although there was a trend in favour of the high dose of edoxaban for lower risk of major bleeding in patients with poor INR control (5).

Exdoxaban is a direct factor $\mathrm{Xa}$ inhibitor with a molecular weight of 548 Dalton. Its protein binding is approximately $54 \%$ and its bioavailability is $50 \%$. Its half-life is around 9-11 hours, and peak plasma levels are reached between the first and second hours after administration. Its excretion is $35 \%$ renal and the rest hepatic (6).

The Food and Drug Administration (FDA) approved the use of edoxaban, under the name Savaysa ${ }^{\circledR}$, in January 2015, and in June 2015, the European Medicines Agency (EMA) authorized its marketing under the name Lixiana ${ }^{\circledR}$. The usual dose is $60 \mathrm{mg}$ every 24 hours, although in patients with renal impairment or low body weight (under $60 \mathrm{~kg}$ ) the dose should be halved to $30 \mathrm{mg}$ daily. The different cost-effectiveness studies on new oral anticoagulants (edoxaban, dabigatran, rivaroxaban and apixaban) conducted in several countries are fairly consistent, showing that the administration of these drugs seems the best option for patients at increased risk for thromboembolic or bleeding complications and those with poor anticoagulation control with vitamin $\mathrm{K}$ antagonists (7).

\section{Material and Methods}

The aim of this paper is to contribute to the discussion on how to approach patients taking edoxaban, before, during and after dental treatments.

In the present contribution we offer an exhaustive review of the literature found in PubMed and Cochrane Library in July 2016. The words used were "edoxaban", "dabigatran", "rivaroxaban", "apixaban", "new oral anticoagulants", "novel oral anticoagulants", "bleeding" and "dental treatment" with the "and" boolean operator. Metaanalyses, systematic reviews, clinical trials and case-control studies were considered. Specialized textbooks were also consulted.

Because of their relatively recent introduction, specific studies regarding dental treatment of patients taking novel oral anticoagulants are available in literature only from 2012.

-Analytical tests

Unlike classic oral anticoagulants that act as vitamin $\mathrm{K}$ inhibitors, such as warfarin and acenocoumarol, edoxaban does not require regular coagulation tests. However, there are certain situations where it may be necessary to assess its plasma concentration, such as overdose, bleeding or emergency surgery. There are no significant changes in the results of routine analytical coagulation tests after the administration of edoxaban. Prothrombin time and activated partial prothrombin time change according to plasma edoxaban concentrations, increasing in a dose-dependent manner $(8,9)$.

The best test to assess edoxaban concentrations is the measurement of anti-factor Xa $(10,11)$.

-Drug-drug interactions

New oral anticoagulants in general, and edoxaban in particular, have few drug-drug interactions. Edoxaban is predominantly absorbed in the upper gastrointestinal tract, so that drugs or conditions that increase gastric emptying and intestinal motility may reduce edoxaban 
dissolution and absorption. Plasma edoxaban concentrations increase when it is combined with ketoconazole, cyclosporine, dronedarone, erythromycin, quinidine or verapamil, and its co-administration with rifampicin leads to a shortened half-life, with possible decreases in its pharmacodynamic effects (12-14).

-Dental management

The prevalence of bleeding complications during invasive dental procedures is higher in patients taking edoxaban and the rest of new oral anticoagulants (15). There are certain dental treatments that require temporary discontinuation of edoxaban before beginning.

There are currently no published studies or protocols in scientific literature on the dental management of patients taking anticoagulants of the type of edoxaban, so that the risk for bleeding should be individually assessed for each patient according to their cardiac and haemorrhagic condition and the bleeding risk involved in the dental procedure to be carried out. While still scarce, there are, however, clinical guidelines published in recent years that describe the perioperative management of patients takin dabigatran, rivaroxaban and apixaban.

Based on the bleeding risk involved in the different dental treatments, they can be classified into procedures with low bleeding risk and procedures with standard and high bleeding risk.

Procedures with low bleeding risk include oral surgery of up to 45 minutes, simple extractions (less than 3 teeth in the same session) and periodontal surgery with low bleeding risk (15-18). According to the studies published on new oral anticoagulants and their dental management, dental procedures with low bleeding risk do not require discontinuation of edoxaban (16-25).

The rest of dental procedures are associated with standard and high bleeding risk, and such cases do require temporary discontinuation of edoxaban. Since there is no scientific basis for discontinuing edoxaban prior to performing dental treatment, when to stop it depends on the pharmacokinetics and pharmacodynamics of the drug and on the patient's renal function (impaired renal function involves slower clearance of the oral anticoagulant by renal excretion) (20-35). Table 1 shows the guidelines for edoxaban discontinuation.

When to resume edoxaban to re-establish therapeutic anticoagulation depends on the patient's haemostasis and on the bleeding risk involved in the dental treatment. In cases of oral surgery with standard bleeding risk, edoxaban can be resumed 12-14 hours after the dental treatment (23-37).

The treatment of bleeding after dental procedures should be individualized according to the severity of the bleeding. In cases of mild bleeding, it is enough to use local haemostatic measures such as sutures, gelatine or cellulose sponges and tranexamic acid mouthwashes, which help to reduce the chance of postoperative bleeding (17-40).

\section{Conclusions}

In dentistry and oral surgery, the major concerns in treatment of patients taking oral anticoagulants or antiplatelet drugs is the risk of haemorrhage

There are several novel oral anticoagulant agents (edoxaban, dabigatran, rivaroxaban and apixaban) that are being increasingly used as an alternative to warfarin and acenocoumarol.

For patients requiring simple dental extraction or minor oral surgery procedures, interruption of edoxaban is not generally necessary, while an higher control of bleeding and discontinuation of the drug should be requested before invasive surgical procedures.

The heath professionals have to consider that the number of patients taking edoxaban is increasing. Since available data are not sufficient to establish an evidence-based dental management, the dentist must use caution and attention when treating patients taking edoxaban.

Table 1. Guide to the suppression of edoxaban.

\begin{tabular}{|c|c|c|}
\hline Renal function (Clcr in ml/min) & Low risk of haemorrhage & $\begin{array}{c}\text { Medium and high risk } \\
\text { of haemorrhage }\end{array}$ \\
\hline$>50$ & 24 hours before & 48 hours before \\
\hline $30-50$ & 48 hours before & 96 hours before \\
\hline
\end{tabular}

\section{References}

1. Falck-Ytter Y, Francis CW, Johanson NA, Curley C, Dahl OE, Schulman S, et al. Prevention of VTE in orthopedic surgery patients: Antithrombotic Therapy and Prevention of Thrombosis, 9th ed: American College of Chest Physicians Evidence-Based Clinical Practice Guidelines. Chest. 2012;141:e278S-325S.

2. Ageno W, Gallus AS, Wittkowsky A, Crowther M, Hylek EM, Palareti G, et al. Oral anticoagulant therapy: Antithrombotic Therapy and Prevention of Thrombosis, 9th ed: American College of Chest Physicians Evidence-Based Clinical Practice Guidelines. Chest. 2012;141:e44S-88S.
3. Budnitz DS, Lovegrove MC, Shehab N, Richards CL. Emergency hospitalizations for adverse drug events in older Americans. N Engl J Med. 2011;365:2002-12.

4. Kato ET, Giugliano RP, Ruff CT, Koretsune Y, Yamashita T, Kiss RG, et al. Efficacy and Safety of Edoxaban in Elderly Patients With Atrial Fibrillation in the ENGAGE AF-TIMI 48 Trial. J Am Heart Assoc. 2016;5:pii: e003432.

5. Giugliano RP, Ruff CT, Braunwald E, Murphy SA, Wiviott SD, Halperin JL, et al. Edoxaban versus warfarin in patients with atrial fibrillation. N Engl J Med. 2013;369:2093-104.

6. Bathala MS, Masumoto H, Oguma T, He L, Lowrie C, Mendell J. 
Pharmacokinetics, biotransformation, and mass balance of edoxaban, a selective, direct factor Xa inhibitor, in humans. Drug Metab Dispos. 2012;40:2250-5.

7. Rognoni C, Marchetti M, Quaglini S, Liberato NL. Edoxaban versus warfarin for stroke prevention in non-valvular atrial fibrillation: a costeffectiveness analysis. J Thromb Thrombolysis. 2015;39:149-54.

8. Morishima Y, Kamisato C. Laboratory measurements of the oral direct factor $\mathrm{Xa}$ inhibitor edoxaban: comparison of prothrombin time, activated partial thromboplastin time, and thrombin generation assay. Am J Clin Pathol. 2015;143:241-7.

9. Furugohri T, Isobe K, Honda Y, Kamisato-Matsumoto C, Sugiyama N, Nagahara T, et al. DU-176b, a potent and orally active factor $\mathrm{Xa}$ inhibitor: in vitro and in vivo pharmacological profiles. J Thromb Haemost. 2008;6:1542-9.

10. Ruff CT, Giugliano RP, Braunwald E, Morrow DA, Murphy SA, Kuder JF, et al. Association between edoxaban dose, concentration, anti-Factor Xa activity, and outcomes: an analysis of data from the randomised, double-blind ENGAGE AF-TIMI 48 trial. Lancet. 2015;385:2288-95

11. Barrett YC, Wang Z, Frost C, Shenker A. Clinical laboratory measurement of direct factor $\mathrm{Xa}$ inhibitors: anti-Xa assay is preferable to prothrombin time assay. Thromb Haemost. 2010;104:1263-71.

12. Lippi G, Favaloro EJ, Mattiuzzi C. Combined administration of antibiotics and direct oral anticoagulants: a renewed indication for laboratory monitoring? Semin Thromb Hemost. 2014;40:756-65.

13. Mendell J, Zahir H, Matsushima N, Noveck R, Lee F, Chen S, et al. Drug-drug interaction studies of cardiovascular drugs involving Pglycoprotein, an efflux transporter, on the pharmacokinetics of edoxaban, an oral factor Xa inhibitor. Am J Cardiovasc Drugs. 2013;13:33142.

14. Mendell J, Chen S, He L, Desai M, Parasramupria DA. The effect of rifampin on the pharmacokinetics of edoxaban in healthy adults. Clin Drug Investig. 2015;35:447-53.

15. Febbo A, Cheng A, Stein B, Goss A, Sambrook P. Postoperative Bleeding Following Dental Extractions in Patients Anticoagulated With Warfarin. J Oral Maxillofac Surg. 2016;74:1518-23.

16. Elad S, Marshall J, Meyerowitz C, Connolly G. Novel anticoagulants: general overview and practical considerations for dental practitioners. Oral Dis. 2016;22:23-32.

17. Tsolka P. Dental Procedures in Patients with Atrial Fibrillation and New Oral Anticoagulants. Arrhythm Electrophysiol Rev. 2014;3:85-9.

18. Mingarro-de-León A, Chaveli-López B. Alternative to oral dicoumarin anticoagulants: Considerations in dental care. J Clin Exp Dent. 2013;5:e273-8.

19. Johnston S. An evidence summary of the management of patients taking direct oral anticoagulants (DOACs) undergoing dental surgery. Int J Oral Maxillofac Surg. 2016;45:618-30.

20. Green B, Mendes RA, Van der Valk R, Brennan PA. Novel anticoagulants - an update on the latest developments and management for clinicians treating patients on these drugs. J Oral Pathol Med. 2016;45:551-6.

21. Costantinides F, Rizzo R, Pascazio L, Maglione M. Managing patients taking novel oral anticoagulants (NOAs) in dentistry: a discussion paper on clinical implications. BMC Oral Health. 2016;16:5.

22. Scott A, Gibson J, Crighton A. The management of dental patients taking new generation oral anticoagulants. Prim Dent J. 2014;3:54-8.

23. van Diermen DE, van der Waal I, Hoogstraten J. Management recommendations for invasive dental treatment in patients using oral antithrombotic medication, including novel oral anticoagulants. Oral Surg Oral Med Oral Pathol Oral Radiol. 2013;116:709-16.

24. Firriolo FJ, Hupp WS. Beyond warfarin: the new generation of oral anticoagulants and their implications for the management of dental patients. Oral Surg Oral Med Oral Pathol Oral Radiol. 2012;113:431-41.

25. Richards D. Guidelines for the management of patients who are taking oral anticoagulants and who require dental surgery. Evid Based Dent. 2008;9:5-6.

26. Thean D, Alberghini M. Anticoagulant therapy and its impact on dental patients: a review. Aust Dent J. 2016;61:149-56.
27 Breik O, Cheng A, Sambrook P, Goss A. Protocol in managing oral surgical patients taking dabigatran. Aust Dent J. 2014;59:296-301;quiz 401.

28. Curtin C, Hayes JM, Hayes J. Dental implications of new oral anticoagulants for atrial fibrillation. Dent Update. 2014;41:526-8,530-1.

29. O'Connell JE, Stassen LF. New oral anticoagulants and their implications for dental patients. J Ir Dent Assoc. 2014;60:137-43.

30. Davis C, Robertson C, Shivakumar S, Lee M. Implications of Dabigatran, a direct thrombin inhibitor, for oral surgery practice. J Can Dent Assoc. 2013;79:d74

31. Romond KK, Miller CS, Henry RG. Dental management considerations for a patient taking dabigatran etexilate: a case report. Oral Surg Oral Med Oral Pathol Oral Radiol. 2013;116:e191-5.

32. Kudsi Z, Dalati MH, Sibai L, Koussayer LT. Management of bleeding disorders in the dental practice: managing patients on anticoagulants. Dent Update. 2012;39:358-60,363.

33. Levy JH, Key NS, Azran MS. Novel oral anticoagulants: implications in the perioperative setting. Anesthesiology. 2010;113:726-45.

34. Crowther MA, Warkentin TE. Bleeding risk and the management of bleeding complications in patients undergoing anticoagulant therapy: focus on new anticoagulant agents. Blood. 2008;111:4871-9.

35. Perry DJ, Noakes TJ, Helliwell PS, British Dental Society. Guidelines for the management of patients on oral anticoagulants requiring dental surgery. Br Dent J. 2007;203:389-93.

36. Lopez-Galindo M, Bagán JV. Apixaban and oral implications. J Clin Exp Dent. 2015;7:e528-34.

37. Kerr R, Ogden G, Sime G. Anticoagulant guidelines. Br Dent J. 2013;214:430

38. Alaali Y, Barnes GD, Froehlich JB, Kaatz S. Management of oral anticoagulation in patients undergoing minor dental procedures. J Mich Dent Assoc. 2012;94:36-41.

39. Wynn RL. New antiplatelet and anticoagulant drugs. Gen Dent. 2012;60:8-11.

40. António N, Castro G, Ramos D, Machado A, Gonçalves L, Macedo $\mathrm{T}$, et al. The debate concerning oral anticoagulation: whether to suspend oral anticoagulants during dental treatment. Rev Port Cardiol. 2008;27:531-44

Conflict of Interest

The authors have declared that no conflict of interest exist. 